\section{The Safe Harbors Youth Intervention Project: inter-sectoral collaboration to address sexual exploitation in Minnesota}

\author{
Laurel Edinburgh, ${ }^{1}$ Emily Huemann, ${ }^{2}$ \\ Kathryn Richtman, ${ }^{3}$ \\ Andrea McDonald Marboe, ${ }^{4}$ \\ Elizabeth Saewyc ${ }^{5}$ \\ 1 Midwest Children's Resource Center, \\ Childrens Hospitals and Clinics of \\ Minnesota; ${ }^{2}$ Sexual Offense Services of \\ Ramsey County; ${ }^{3}$ Juvenile Justice \\ Division, Ramsey County Attorney's \\ Office; ${ }^{4}$ Independent consultant service, \\ St. Paul, Minnesota, USA; ${ }^{5}$ University of \\ British Columbia School of Nursing and \\ Division of Adolescent Medicine, \\ Vancouver, Canada
}

\section{Abstract}

The authors aimed to evaluate the Safe Harbors Youth Intervention Project inter-sectoral collaboration to improve continuity and appropriateness of services for sexually exploited children and adolescents. The study was carried on through an intensive, single case study, drawing on interviews and focus groups with experiential youths $(\mathrm{n}=125)$ and multi-sectoral stakeholders $(\mathrm{n}=196)$, documented activities, and repeated interviews with collaborating team members $(n=29)$, teen clients $(n=46)$ and parents $(n=22)$. The collaboration was designed around an eight-step process for creating victim-centered protocols within and across organizations, altering services to bridge gaps in care, and creating training tools for the different sectors. The results of the study showed an initial needs assessment documented fragmented care and problematic communication across departments and sectors. The shared protocol development among decision makers from each agency, focused on best practices and evidence-based interventions, fostered trusting relationships, improved awareness of different roles and services, and speeded practice changes to remove barriers to care for sexually exploited youths. A task-focused collaboration with a shared community-wide protocol, increases transparency between services, and ongoing inter-sectoral training helps healthcare team foster a meaningful response to sexually exploited youths.

\section{Introduction}

Commercial sexual exploitation of children and adolescents occurs in communities throughout North America. It is not a new phenomenon, but since the United Nations Convention on the Rights of the Child (UN CRC) was adopted in 1989, specifically with its Article 34 against sexual exploitation of children and youths, ${ }^{1}$ there has been a growing awareness of societal responsibility to protect vulnerable youths from these forms of abuse, and to help address the health and social sequelae experienced by victims. Even though the full Convention has not yet agreed, the United States has already signed and ratified the Convention's Optional Protocol in 2000 on the sale of children, child prostitution, and child pornography. ${ }^{2}$

Sexual exploitation is not just a legal or child protection issue. Exploited youths face higher risks for several health issues, including violence exposure, depression, self-harm and suicide attempts, substance abuse, sexually transmitted infections and early pregnancy. ${ }^{3-6}$ Sexual exploitation is also linked to inequities in the social determinants of health, as homeless and street-involved youths, youths in the foster care system, and living in poverty are disproportionately more likely to be exploited. Moreover, exploited youths may have limited opportunities for education, legal employment, and social support.7,8

Addressing the complex health and psychosocial needs of sexually exploited youths requires a variety of services, from a number of different sectors. Law enforcement, juvenile justice, child welfare, health care, public health, education, mental health, street outreach, and emergency shelter services all encounter sexually exploited youths, and may have a role in fostering their health and wellbeing. Because these sectors include government departments from municipal, county, and state levels, as well as local and regional nonprofit agencies, and public and private health care settings, inter-sectoral collaboration, especially as a coalition or network, is the most feasible approach to integrating services and improving the continuum of care. ${ }^{9}$ Public health practice can involve coalition-building and community organizing as population interventions for addressing problems that involve multiple sectors. ${ }^{10}$

In 2006, the Minnesota Legislature passed a human trafficking bill. The bill included provisions promoting the creation of novel pathways for youths involved in prostitution to access services, and the collaboration of service providers to provide these needed services. The bill allocated funding to develop joint protocols across multiple sectors, implement the new protocols, train service providers from
Correspondence: Elizabeth M. Saewyc, UBC School of Nursing, T201-2211 Wesbrook Mall Vancouver, BC V6T 2B5 Canada.

Tel: +1.604-822.7505 - Fax: +11.604.822.7466; Mobile: +1.778 .386 .1051 .

E-mail: elizabeth.saewyc@nursing.ubc.ca

Key words: sexual exploitation, sexual abuse, intersectoral collaboration.

Contributions: LE, EH, KR, collaboration and project development; EH, AMDM, interviews and surveys performing; $\mathrm{LE}, \mathrm{EH}, \mathrm{ES}$, police participation evaluation; LE, ES, Runaway Intervention Services evaluation; AMDM, evaluation conceptual framework providing; LE, EH, KR, AMDM, ES, manuscript analysis and drafting; ES, final revised draft.

Acknowledgments and Funding: the Safe Harbor for Youth Intervention Project was funded by a one-time grant from the Minnesota State Legislature. Evaluation of some outcomes of the collaboration were funded by a grant from the Minnesota Department of Public Safety (Richtmann, PI) and in part by grant \#CPP 86374 from the Institute for Population and Public Health, Canadian Institutes for Health Research (Saewyc, Applied Public Health Research Chair). Thanks to Partners for Violence Prevention, for providing staff to facilitate the SHYIP collaborative meetings, and elements of the community needs assessment.

Conflict of interests: the data collected in the community needs assessment, as well as in the outcome evaluations of the different portions of the SHYIP collaboration, conformed to the ethical standards of research in the United States, including IRB approval through both Children's Hospitals and Clinics of Minnesota, and the Behavioral Research Ethics Board of the University of British Columbia, where required. The authors declare they have no conflict of interests.

Received for publication: 8 August 2011.

Revision received: 9 January 2012.

Accepted for publication: 11 January 2012.

This work is licensed under a Creative Commons Attribution NonCommercial 3.0 License (CC BYNC 3.0).

CC Copyright L. Edinburgh et al., 2012

Licensee PAGEPress, Italy

Nursing Reports 2012; 2:e4

doi:10.4081/nursrep.2012.e4

these multiple sectors, and evaluate the community interventions that were developed to assist sexually exploited youths. Ramsey County, whose largest city is St. Paul, was selected as the geographic region in which to target this program. Ramsey County was selected for two reasons: first, the county already had a strong interdisciplinary sexual assault protocol team that had developed joint protocols for providing services to adults who 
are sexually assaulted, and second, there was an existing inter-sectoral coalition to help young Southeast Asian girls who had been sexually exploited. This coalition involved many of the relevant government and non-governmental agencies and services. ${ }^{11}$ The Minnesota legislature passed a supplemental appropriations bill granting Ramsey County funds to implement the Safe Harbors Youth Intervention Project (SHYIP), a pilot project to address the needs of sexually exploited youths.

SHYIP was developed in Minnesota by service providers from multiple sectors to coordinate the care provided to youths that are homeless, runaway or truant and had been or were at risk of being sexually exploited. The goal of the project was to create common pathways for each discipline to utilize when providing services to youths who have run away and are being sexually exploited. The purpose of this case study is to report the processes by which SHYIP accomplished their inter-sectoral collaboration, and some of the resulting outcomes to date in changing services.

Although there are a number of different definitions and terms used to describe children and youths who have been sexually exploited, the UN CRC Article 34 identifies sexual exploitation as the exploitative use of children in prostitution or other unlawful sexual activities, and the Optional protocol defines child prostitution as the use of a child in sexual activities for remuneration or any other form of consideration. ${ }^{2}$ We will use the terms youths involved in prostitution and sexually exploited youths interchangeably throughout this paper. In the SHYIP collaborative youths were considered sexually exploited if sex was exchanged for money or other considerations, such as the use of a cell phone, food, shelter, or a perceived relationship with an adult.

\section{Materials and Methods}

As the primary strategy for creating an effective inter-sectoral collaboration, SHYIP was organized around the goal of developing both internal and interagency protocols for addressing the needs of sexually exploited adolescents. SHYIP used an eight-step model for protocol development originally designed for improving services for crime victims. ${ }^{12}$ The eight steps involved: introducing the concept of multi-sectoral protocol development to relevant stakeholders and inviting their membership in SHYIP; developing an inventory of existing services; conducting a needs assessment by eliciting the perspectives of experiential youth and various service providers who come in contact with sexually exploited youths; drafting the protocols; renewing interagency agreements; training service providers; and documenting the changes that resulted from the new collaborations. Experiential youths self-identified as having runaway, been homeless and/or sexually exploited and services providers were chosen based on their experience with the target population. An independent consultant facilitated the SHYIP project and coordinated the steps of protocol development among all the agencies, leading a team that included one person with decision-making authority from each of the community partners and government agencies. These members of the SHYIP team committed to participating in the protocol development process and acting as the communication link between their agency and the SHYIP team. An independent evaluator was also subsequently involved in documenting changes that resulted from the collaboration, and collecting data about the collaborators' perceptions of their collaboration, as well as beginning to document the effectiveness of changes in practice.

The procedures and data collection methods for each stage are described below.

\section{Introducing SHYIP and securing membership}

The first step was introducing the concept of inter-agency protocol development to the key stakeholders serving sexually exploited youths in Ramsey County. Municipal, county, community and nonprofit agencies that would likely be in contact with sexually exploited youths were invited to a community meeting to explain the intent of the legislation and the protocol development process, and asked to join the SHYIP team. Commitment to SHYIP included representation at monthly team meetings, reviewing and revising internal and external protocols related to the target population, and conducting internal agency training on the completed protocols. All members of the team signed a memorandum of understanding that they would commit leadership staff time and resources to this project. Table 1 indicates a list of the organizations that have been members of the SHYIP.

\section{Inventory of existing services}

The inventory of existing services involved the various members of the team identifying their own resources, services and eligibility criteria, as well as the agencies to which they referred clients to. The resulting inventory eventually formed the basis of a comprehensive resource list for professionals and for youths, that was made available in print and on the Internet.

\section{Needs assessment among experi- ential youths (focus groups and interviews)}

Self-identified runaway, homeless, and sexu-
Table 1. Safe harbors youth intervention project organizational members.

Advocacy groups for sexual assault and for homeless youth

Law enforcement (city and county agencies)

County attorney's office

Medical providers

Teen clinics

School based clinics

Sexual assault nurse examiners

Hospital-based child advocacy center (child abuse service)

Street outreach workers

Emergency shelters

Ramsey County agencies

Community corrections

Juvenile corrections

Child protection

Children's mental health

Sexual offense services

St. Paul school district truancy intervention program

ally exploited youths $(n=137)$ were recruited from 16 agencies from different sectors that provided a wide variety of services, including school programs, homeless shelters, drop-in centers (including one for sexual minority youths), crisis support programs, and health care services. In 2007, short surveys were distributed to homeless, runaway or at-risk youths to solicit their input on their experience with various agencies they may have accessed. These surveys were developed in partnership with the agencies that commonly worked with this population, to ensure the questions were relevant to their service. These youths were then invited to participate in either focus groups with six to nine youths, or one-on-one interviews with the evaluator. Since one of the critical traumas experienced by runaway, homeless, and sexually exploited youths is the loss of safety and control over fundamental aspects of life, each youth chose the setting in which they wanted to be interviewed. This approach was designed to empower the teen's participation in the evaluation.

The majority of the participants were girls. The independent evaluator met with youths individually that responded to a poster invitation or word of mouth. Whereas in most organizations, the teens participated in focus groups of up to 12 people, in some organizations, they had individual interviews. The focus groups and interviews asked a series of questions about different service providers, including police, probation officers, attorneys, social workers, health care providers, social service agencies and nonprofit organizations. Questions assessed youths' experiences with each type of provider, whether the providers 
met the teen's needs, and if help was available in their first language. The focus groups also included questions about additional services that might be needed, what kinds of things adults could do to gain their trust, and who they turn to for help with problems.

\section{Stakeholder/service provider focus groups}

In the early stages of the project, 18 focus groups/forums were held with community stakeholders from the various government sectors, health care, and private non-profit groups $(\mathrm{n}=196)$. Table 2 lists the types of stakeholders and organizations where focus groups or forums were held, with the sample participating from each. The goal was to gain information from professionals about their views of and experiences with the target population. The questions focused around what other agencies that each type of provider commonly worked with, those they commonly referred to be exploited youth to, the barriers that they encountered in working with these agencies, gaps they identified in services for exploited youths, and advice they could offer for working effectively with this population.

Focus groups were chosen as a way to gather information from a variety of provider perspectives about the same topic and gain insight into people's understanding of the target population. The focus group format was used to gather information and limit the amount of time that any agency had to a lot to this aspect of the project. The format allowed the greatest number of agency personal to participate in the project.

\section{Drafting the protocols}

Writing and sharing protocols was an expected goal of the SHYIP team. Each organization that interacted with adolescent victims of sex trafficking explored the evidence and best practices for the interventions they provided, as well as considering gaps in their services based on the community needs assessment. They then developed or refined their internal organization protocols and evidencebased guidelines, and shared them with the rest of the SHYIP team. All the protocols were designed to be victim-centered. Together the team also developed a joint external protocol for how the organizations should work together in meeting the continuum of care for sexually exploited youths.

\section{Renewing interagency agreements}

Once the new protocol was written, agencies were again asked to recommit to being a SHYIP member. New memoranda of understanding were developed and signed, and each agency agreed to train their own personnel on their new guidelines and evidence-based

Table 2. Safe Harbors Youth Intervention Project provider focus groups (number of participants).

Advocates for sexual assault survivors-breaking free and sexual offense services

Ramsey County Court guardian ad litems

11

Child advocacy center clinical staff and Ramsey County emergency department's sexual 14 assault nurse examiner managers

\begin{tabular}{lc} 
Saint Paul public school social workers & 8 \\
\hline Saint Paul public schools - junior high school counselors & 13 \\
Saint Paul Ramsey County department of public health managers & 8 \\
\hline Saint Paul police department juvenile unit and student resource officers & 22 \\
Ramsey County Attorney's office lawyers and staff & 10 \\
\hline Ramsey County child protection managers & 13 \\
Ramsey County child protection staff & 6 \\
\hline Ramsey County children's mental health case managers & 15 \\
Ramsey County delinquency probation officers & 10 \\
\hline Ramsey County foster care licensing staff & 16 \\
Ramsey County juvenile corrections and County juvenile detention center staff & 8 \\
\hline Ramsey County suburban school staff & 6 \\
Ramsey County Sheriff's and suburban law enforcement officers & 3 \\
\hline Ramsey County Sheriff's and suburban law enforcement student resource officers & 11 \\
Youth services providers & 10 \\
\hline
\end{tabular}

interventions. Each agency could request SHYIP members from other organizations to come explain their guidelines, so that all the SHYIP organizations would understand each others' roles in providing services. As part of the on-going commitment, agencies were asked to attend monthly meetings to discuss trainings completed, new projects being implemented, and problems between agencies or challenges in providing services to sexually exploited youths.

\section{Training}

An education subcommittee was created to establish training tools for the organizations. The tools included a comprehensive protocol book, where each agency's guidelines for working with youths in prostitution was published, both in book form and on-line, as well as a comprehensive resource list for professionals and for youths, and a cultural awareness companion guide. The education subcommittee also created a training video in partnership with experiential youths, that provided information about the issues that the sexually exploited youths regularly face, as well as key messages for building trust and improving practices. Finally, they developed resources for parents and other adults on how to respond when a teen runs away.

\section{Evaluating changes in collaboration and practices}

At their regular meetings, the SHYIP team reported changes in services and protocols within their organizations, and documented new collaborative efforts and trainings. In addition, one of the key inter-sectoral collaborative programs, the Runaway Intervention Project for sexually exploited young runaways, retained an external evaluator. ${ }^{13}$ Besides documenting the interventions and monitoring the effects of services in that specific program, ${ }^{14}$ from 2007 to 2010 the evaluator conducted yearly interviews with staff from many of the collaborating organizations, to identify the perceptions of the collaboration, the challenges encountered, and activities and changes in their programs since SHYIP began. There were 56 interviews involving 29 different people, including health care providers, social workers, school counselors, county attorneys, police officers, sexual assault victim advocates, outreach staff, and case managers. Because the goal of collaboration was to improve services for exploited youths and their families, the evaluator also interviewed 46 clients and 22 parents over those four years who accessed different services. These semistructured interviews were conducted primarily face-to-face, with translators provided for Southeast Asian and Latino parents when needed $(n=9)$. Analyses of these interviews were primarily focused on potential improvements to the services as an internal evaluation; however, for this case study, we have conducted a secondary analysis of those responses to incorporate observations from the service providers, referring agency staff, and parents as they relate to the collaboration between the services. 


\section{Results}

\section{Focus groups with service providers}

The community needs assessment strategies identified a number of challenges to providing the range of services needed by runaway, homeless and/or sexually exploited teens. In the forums with service providers, they identified system issues of poor communication between government agencies, such that between child protection, law enforcement, and corrections. Providers in the nonprofit sector often offered services in isolation; there was limited collaboration between organizations, but rather competition for existing limited funding to provide care for sexually trafficked youths. Government agencies missed or ignored youths who were being sexually trafficked. People working in nonprofit organizations and those in government agencies often misunderstood each others' roles, and privacy concerns around data sharing prevented them from sharing information, even when two divisions within the same agency were both working with the youths or their families. For example, a mental health worker might be working with the youth or an adult family member with mental illness, and human services staff would not have this information. If the youths accessed community agencies independently (i.e., without a referral from a case manager) the type of help offered would be usually unknown to human service workers who were also assigned to support the teens. Youths, parents, and service providers all identified a lack of communication and continuity of care.

\section{Interviews and focus groups with experiential youths}

The results of the youths experiential surveys were difficult for some SHYIP team members to hear, because the overall tone was that many professionals were viewed as unhelpful. Youths often reported negative interactions with law enforcement. For example, a girl said that they were treated like a kindergartner by the police. An overwhelming majority of the experiences with non-profit, youths serving organizations was positive. Positive responses centered on the youths' feeling treated with respect, support, and being included; they felt staff were open to share stuff. Negative comments centered on a few organizations and were generalized as bad by the youths and did not meet their needs. Multiple youth responded that everything takes too long.

Most youths did not know about available health care or community agency resources, suggesting that outreach services were not reaching their target youth populations. The youths frequently mentioned there were no shelter beds available in the community; they did not want to have to involve police or human services staff in order to secure shelter. The youths repeatedly identified that providers needed to develop trust and rapport with the youths before any services would be accepted.

The majority of the youths' experiences with police, juvenile court officials and probation officers were related to status offenses. A status offense is a violation of the law based on age such as truancy, running away and curfew violations. Comments from the youths who had interactions with the juvenile criminal justice system were resoundingly negative. One youth reported everyone makes decisions about me without asking me. Probation officers were described as people who did not care, someone who doesn't pay attention to my needs and who only work to get money. The youths had complaints that social workers got into their business, and they were being pressured, and having to involve parents.

Perceptions of health care providers varied. One youth said, Every time I go to the clinic, they ask me questions with my mom there, so I lie, and another had a similar comment: We cannot be honest with our parents there. Conversely, other youths said that members were helpful, good and made me feel at ease. Other observations mentioned several times in focus groups included that clinics had long waits, hectic environments, it was difficult to read forms, and staff repeatedly asked me the same questions.

\section{Creating new protocols and chang- ing practices}

SHYIP members used the youths' and service providers' information from the community needs assessment in changing practices within their own agencies and when starting to write protocol. During the process of writing the protocol and sharing their newly written guidelines with the other members of the SHYIP team, agencies began to acknowledge where their own gaps in providing services existed. They also recognized that evidence in how to intervene with sexually exploited youths was often lacking or non-existent. This provided a catalyst for agencies to initiate novel interventions, and collaboration created cross-training opportunities.

From its inception, the SHYIP team was action-oriented, and members were challenged to work on changes they could make within their own organization or jointly to improve practices for interacting with sexually exploited runaways. Since multiple agencies attended every meeting, information sharing occurred between systems. Leadership in each agency heard about the frustration and challenges that occurred when another SHYIP agency tried to access their services and encountered barriers. This often resulted in an immediate internal policy change. For example, when a runaway youth in the juvenile detention center (JDC) disclosed a recent sexual assault and was brought to the local hospital, the sexual assault nurse examiner discovered the victim had been made to shower as part of the JDC intake process, effectively washing away any DNA evidence. JDC staff had always provided the youth a shower before conducting their assessment of abuse, health and safety. After this discussion at SHYIP, JDC changed their intake processes, and all youths were asked about being forced to have sex within the last five days before they were asked to shower. The sexual assault victim advocacy service in the county public health department, also part of SHYIP, provided training to the JDC staff on how to ask about sexual abuse and exploitation.

A number of other innovations occurred as part of the collaboration. For example, the police realized that they were chasing runaways but had no way to assess risk of sexual exploitation or even abuse at home, or to refer the youths to existing services. A commander in the police department and a nurse clinician from the Child Advocacy Clinic developed a short 10-question screening instrument that could be used by all law enforcement officers who came into contact with a runaway youth. The goal was for the youths to be provided with immediate intervention, if necessary, or be referred to services in school or from a community agency. In order to implement this department change, the entire police department was trained in how to use the tool and subsequently the practice of asking the 10 Questions became integrated into regular practice. A recent evaluation of this new screening practice suggests it has increased early identification of youths who have been sexually assaulted or exploited while a runaway, and has helped the majority of these access health care services. ${ }^{15}$

As another outcome, the St. Paul school district realized they needed to be better able to identify homeless and runaway youths within schools. School district SHYIP team members felt school staff would be hesitant to ask students about these sensitive topics unless they were also aware of school and community resources immediately available and accessible to help. A mandatory training was developed and provided to all teachers and staff about truancy, running away, and sexual exploitation. In cooperation with a street outreach agency, a comprehensive list of youthfriendly services were posted on the school district's intranet.

The county attorney's office developed policies relating to the charging and prosecution of cases involving adolescent victims of sexual exploitation; one of the critical elements of the 
protocol was developing internal standards for communication and coordination when cases overlapped. In particular, the standards addressed inter-departmental communication when runaways who are victims in an adult prosecution case are also part of a child welfare case. This new protocol requires attorneys from different divisions to consult with other to ensure cases are handled in a way that promotes a better outcome for the youths.

In addition to helping with training throughout the different agencies and government departments, the sexual assault advocacy service identified additional team members to invite to SHYIP, including anti-prostitution advocacy groups, culturally diverse service agencies, and stakeholders within public health departments. They also changed their services, committing to meet clients and their family members at the hospital-based child advocacy center, to provide advocacy, support and follow-up services at the point of medical assessment and treatment.

Working together to draft protocols among and between the county's corrections services and human services (child welfare and mental health) departments was particularly informative; the protocol development discussions revealed long-standing misunderstandings of process between agencies. The drafting process also resulted in new intake and placement protocols; the juvenile detention center updated its risk assessment to determine placement, returning low-risk youths to their homes, placing moderate-risk youths in alternative housing, and reducing overall the number of youths held in JDC. Similarly, child protective services outlined how multiple departments within their agency could better address the needs of runaway youths. The crisis mental health team received additional training, and due to working with the SHYIP team, expanded the settings to which they would respond. An example would be that the crisis mental health unit might now respond to a non-profit agency and supplement available services. Another example of agency change was having supervisors of different divisions meet when a client and their family were receiving services from different groups of professionals within the same agency. Child protection workers, probation officers, and detention center staff all received interdisciplinary training on working with sexually exploited youths.

One of the glaring challenges for the youths to be identified by Corrections and Human Services were the growing number of runaway and homeless youths, and a profound lack of shelter beds, already noted by the teens in the needs assessment. Links were made between shelter programs and county agencies through a subsequent initiative, the Ramsey County Youth Emergency Shelter team, funded by the
Minnesota Office of Justice Programs. The hospital-based child advocacy center (child abuse clinic), which had already played a key role in developing the inter-sectoral Runaway Intervention Project for sexually exploited runaway girls, ${ }^{14}$ used the collaborative SHYIP process to increase awareness about their intervention services across sectors. Based on the needs assessment, they also changed practices, such as providing all youths with immediate access to hormonal contraception, obtaining permission to share health information between the center and the teen's schoolbased health clinic, and providing the Human papilloma virus vaccine. Priority appointments were now provided to youths who were at high risk of running away again, even if there was no known history of sexual exploitation.

\section{Observations and changes in col- laboration during SHYIP}

The annual interviews with the front-line staff and managers in the different SHYIP member services provided perspectives on the collaboration itself. Managers talked more critically of the difficulties of collaboration, especially with high staff turnover in some organizations making it hard to keep staff aware of other services' different roles. In contrast, front-line workers identified improved communication, greater awareness of other services' eligibility criteria, and swifter access to needed services for the exploited teens they worked with, in part because the protocols removed barriers, but also the relationships that grew from the SHYIP collaborations made it easier to trust services.

Law enforcement identified clear benefits of having better relationships with existing services. As one officer stated:

A lot of times we encounter runaways, sometimes parents don't know what to do, and I tell you, the one thing you absolutely cannot do, as law enforcement, is to say, 'I don't know...I can't help you.' It's the worst thing. They expect us to have the answers, to be able to help. So now, when I have resources to tell people, they don't feel like I'm passing the buck.

Police also mentioned that other communities kept trying to transfer cases to their jurisdiction, so that the girls and families become eligible for services, since nothing similar is available in their community.

Parents and sexually exploited youths who were interviewed made similar comments on finding services prompt in responding, and access to other needed services facilitated by the relationships between organizations. In the first two years, parents and teens had complaints about some specific services that seemed less responsive or unavailable, but in the subsequent two years, teens and parents were generally positive about all the different services they accessed within the SHYIP col- laborative. As one parent explained:

I'm satisfied with the program, and impressed and pleased with all the services that are provided. It's wonderful to have it all in place for her, if I had to run around and try to get each of these things set up, it would be hard, some of them have waiting lists for appointments of 3 months or more, and these are things that [my daughter] really needs.

Even the recommendations from parents were focused more around extending the collaboration rather than changing it. For example, another parent stated, They should have more programs like this. Spread the word, have other facilities do this too. Advocate for more organizations to get involved to provide a service for parents. In 2009 , the agencies and community partners identified the loss of services throughout the community with the economic downturn, and worried about the security of funding for the new services that had been developed as part of SHYIP, both those in the non-profit and health care sectors that rely on grants, and those in government agencies that experienced significant budget cuts. Repeatedly, agencies and referring partners, as well as parents, suggested the biggest improvement would be to ensure the funding to keep these important new services going. For example, one of the agency partners explained, That it would no longer rely on external funding streams, i.e., grants, that it would become part of the county budget, and so we could build capacity to serve more youths - open the doors to all girls and boys, while a parent said, Don't let the system take it away, and a staff member from one of the referring agencies said, I would like to have it not be soft money, be permanent.

Parents and teens also reported improvements in health and psychosocial outcomes among the exploited youths. One of the girls who had been involved for nearly a year said, I know a couple girls who have been involved with the program who have really changed: they're not running no more, not doing drugs, they're going to school. It's been really helpful. Parents whose daughters had been in the program for more than a month all reported seeing improvement when their teen was participating regularly in the various groups and home visits; as one said, She was doing better because she could talk things out, deal with her frustrations. Nearly all said they would recommend the program to their relatives and friends whose daughters might also be having troubles. Indeed, a few of the parents indicated they already had recommended the program, and those girls had become involved.

The outcomes for sexually exploited youths that were identified by these annual stakeholder interviews, were further validated through a host of metrics: ongoing quarterly evaluations of their trauma symptoms, risk behaviors, 
enhanced self-esteem and school performance, fewer episodes of running away and by improved connections to family and school. Although only the 2006-2007 outcomes for sexually exploited girls have been published to date, ${ }^{14}$ the outcomes for girls enrolled in subsequent years, which have been reported to the collaborating agencies and the funders, remain consistently strong.

\section{Discussion}

Inter-organizational or inter-sectoral collaboration can be challenging, especially when it requires voluntary involvement among autonomous groups with separate hierarchical structures. ${ }^{9}$ In public health, this collaboration often takes the form of multidisciplinary teams focused around providing services to a specific population. A difficulty of this form of collaboration, as Axelsson and Axelsson ${ }^{9}$ noted, is that team members may feel themselves torn between the teams and their respective organizations (p. 82). Although the SHYIP collaboration did involve a multidisciplinary team of representatives from each agency, a key difference in their collaboration was that they were focused on protocol development and improved collaboration among their agencies, not solely collaboration around specific clients and their needs. This is more akin to coalition-building forms of inter-sectoral collaboration, which is a form of collaboration that public health nurses may help foster. ${ }^{10,11}$ Involving decision makers and front-line staff in SHYIP created partnerships and exposure to others' work, and began a process where disparate groups informed each others' practices and understanding of the needs of sexually exploited youths. Focusing on a mutual task, in this case protocol development both internally and jointly across agencies, appeared to result in more systemic changes to alter fragmented and disconnected services, an important strategy for effective coalition-building. ${ }^{10}$ It also helped foster joint norms and values between organizations, an important requirement for effective collaboration. $^{9}$ Several offshoot projects, changes in practice, additional grant funding, and extensive training was spurred by the SHYIP team collaboration.

Stable, ongoing teams are important for sustainable inter-sectoral collaboration in public health. ${ }^{9}$ The renewal of the memoranda of understanding after protocols were developed, and ongoing monthly meetings, were two strategies for sustaining the collaboration, as well as the continuous evaluation of processes and the outcomes. Ultimately, the evaluation of the intersectoral collaboration will rest on whether more sexually exploited teens are reached and have their needs met within the collaborative services; such evaluation is already in process.

Experience with inter-sectoral collaboration revealed a numbers of lessons that are applicable to other inter-sectoral partnerships that align to address broad issues that impact multiple agencies. Multi-sector collaborations need to have a common vision and goals, ${ }^{10}$ which helps transcend the difficulties that could develop when agencies learn they may not be helping each other or their targeted clients as intended. The large group SHYIP meetings functioned best when there were narrowly focused agenda items that allowed time for discussions of process as well as writing the protocol. The leadership staff of each agency needed to commit to the long-term project and to making practice changes within their own organization that reflected the protocol that was written as part of the collaboration. The member(s) of the SHYIP team from each agency needed to continually reach out within their own agency to communicate how current practices were viewed by other community partners, and most importantly, how they were viewed by the target population of youths. Another important factor in determining the success of the collaboration was a belief from all partners that there was parity in decision-making and in determining priorities. In order to address the large scale and diverse issues identified in the community needs assessment, each agency needed to have the ability to commit time, energy and resources to the project.

There were also challenges in developing an inter-sectoral model of collaboration. The SHYIP team had difficulty determining agency competency to serve the target population, and knowing whether the interventions developed would be sustainable. At times, agencies that were key to writing the protocol missed the large group SHYIP meetings, or directors within their own organization were reluctant to change current practices because of resources that would be needed for retraining staff. Another difficulty encountered was that sometimes a champion for change within an organization would leave their position for another job, and the momentum in that organization would slow. In order to tackle these challenges it was important to have a tight time-line for the eight-step model used by the SHYIP team for transforming current practice.

There are a few limitations of this study that should be considered when generalizing the needs of sexually exploited youths in other communities and this approach to addressing these needs. First, this was a single case study, within a specific context in the mid-western United States. Thus, some of the results may be due to the context and existing political and professional relationships. For example, although the project did not begin with a spe- cific coalition model, some of the participants had previously participated in the Hmong Youth Task Force, another community developed action oriented coalition that focused on addressing the priorities and needs of a subpopulation of sexually exploited youths. ${ }^{11}$ As a result, some of the government service providers who already had working knowledge of different services provided by each agency may have been able to trust other partners because of these previous contacts, and this may have facilitated the ease of protocol development. Second, the needs assessments (focus groups with stakeholders and surveys of the youths) relied on convenience sampling of key informants, and thus may have missed some of the youths and the agency providers who had very different experiences and perspectives. Third, while the short-term outcomes of the inter-sectoral collaboration have been documented, there continue to be ripple effects of the project that have yet to be evaluated, and it is difficult to assess how many exploited youths have been further helped as a result of the changes brought about by the collaboration. Finally, it is too soon to determine the sustainability of the collaboration's impact, especially with challenging economic times leading to government budget cuts. Despite these limitations, the current results show significant promise as a strategy for changing the climate for addressing the needs of sexually exploited youths

How a community is prepared to identify and respond to the needs of sexually exploited youths depends on preparation. Having a community-wide protocol, transparency between services, and ongoing training helped foster a meaningful response to sexually exploited youths.

\section{References}

1. Office of the United Nations high Commissioner for Human Rights Optional Protocol to the Convention on the Rights of the Child on the sale for children, child prostitution and child pornography. 2002. http://www2.ohchr.org/english/law/crcsale.htm Accessed: December 23, 2010.

2. United Nations Treaty Collection. Chapter IV, Human Rights. 11c. Optional Protocol to the Convention on the Rights of the Child on the sale of children, child prostitution and child pornography. 2010. http://treaties.un.org/pages/ViewDetails.as px?src=IND\&mtdsg_no=IV-11-c\&chapter $=4 \& l a n g=e n$ Accessed: December 23, 2010.

3. Edinburgh L, Saewyc E, Thao T, Levitt C. Sexual exploitation of very young among girls. J Adolesc Health 2006;39:111-8. 
4. Parriott AM, Auerswald CL. Incidence and predictors of onset of injection drug use in a San Francisco cohort of homeless youth. Subst Use Misuse 2009;44:1958-70.

5. Roy E, Haley N, Leclerc P, et al. Prevalence of HIV infection and risk behaviours among Montreal street youth. Int J STD AIDS 2000;11:241-7.

6. Tyler KA, Hoyt DR, Whitbeck LB, Cauce AM. The effects of a high-risk environment on the sexual victimization of homeless and runaway youth. Violence Vict 2001;16: 441-55.

7. Saewyc EM, MacKay L, Anderson J, Drozda C. It's not what you think: sexually exploited youth in British Columbia. Vancouver: University of British Columbia; 2008.

8. Wilson HW, Widom CS. The role of youth problem behaviors in the path from child abuse and neglect to prostitution: a prospective examination. J Res Adolesc 2010;20:210-36.

9. Axelsson R, Axelsson SB. Integration and collaboration in public health--a conceptual framework. Int $\mathrm{J}$ Health Plan Manage 2006;21:75-88.

10. Keller LO, Strohschein S, Lia-Hoagberg B, Schaffer MA. Population-based public health interventions: practice-based and evidence-supported. Part I. Public Health Nurs 2004;21:453-68.

11. Saewyc EM, Solsvig W, Edinburgh L. The Hmong Youth Task Force: evaluation of a coalition to address the sexual exploitation of young runaways. Public Health Nurs 2008;25:69-76.
12. Boles A, Patterson J. Improving community response to crime victims: an eight-step model for developing protocol. Thousand Oaks: Sage; 1997.

13. Edinburgh LD, Saewyc EM. A novel, intensive home-visiting intervention for runaway, sexually exploited girls. J Spec Pediatr Nurs 2009;14:41-8.

14. Saewyc EM, Edinburgh LD. Restoring healthy developmental trajectories for sexually exploited young runaway girls: fostering protective factors and reducing risk behaviors. J Adolesc Health 2010;46:180-8.

15. Edinburgh LD, Huemann E, Saewyc EM. The 10-Question Tool for police officers: A novel health and psychosocial screening instrument for runaway youth. OJJDP J Juv Justice 2011. [In press]. 